\title{
Supprting Information
}

\section{Controlled Synthesis, Characterization and Crystallization of Ni-P Nanospheres}

Songhai Xie, Minghua Qiao, Wuzong Zhou, "Ge Luo, Heyong He, Kangnian Fan *

Tiejun Zhao, and Weikang Yuan
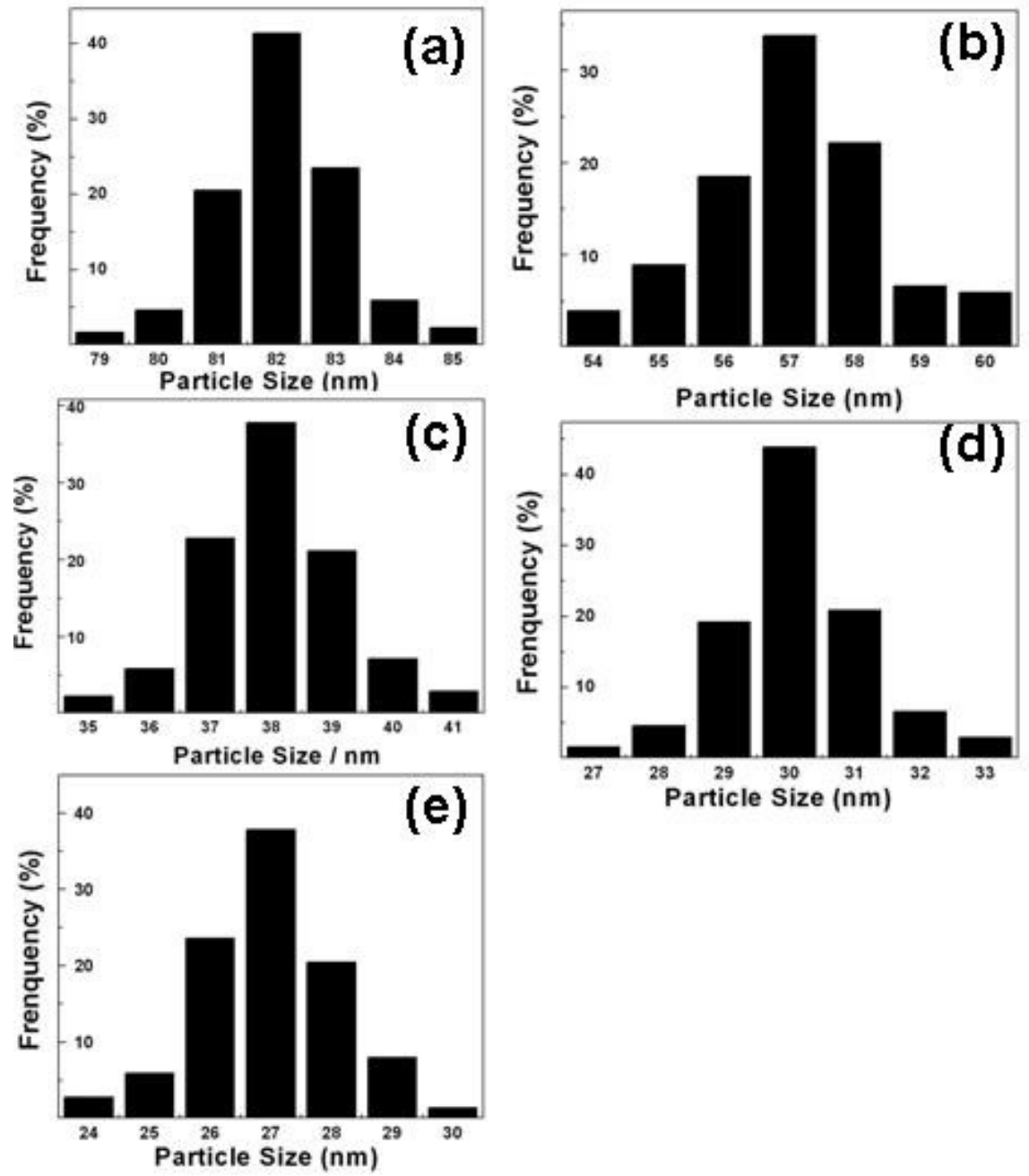

Figure S1. Particle size distributions of the R-series Ni-P amorphous nanospheres, prepared using different starting ratios of $\mathrm{H}_{2} \mathrm{PO}_{2}{ }^{-} / \mathrm{Ni}^{2+}$, (a) 2.2, (b) 4.4, (c) 6.6, (d) 8.8 , (e) 11.0, corresponding to the TEM images in figure 1. 

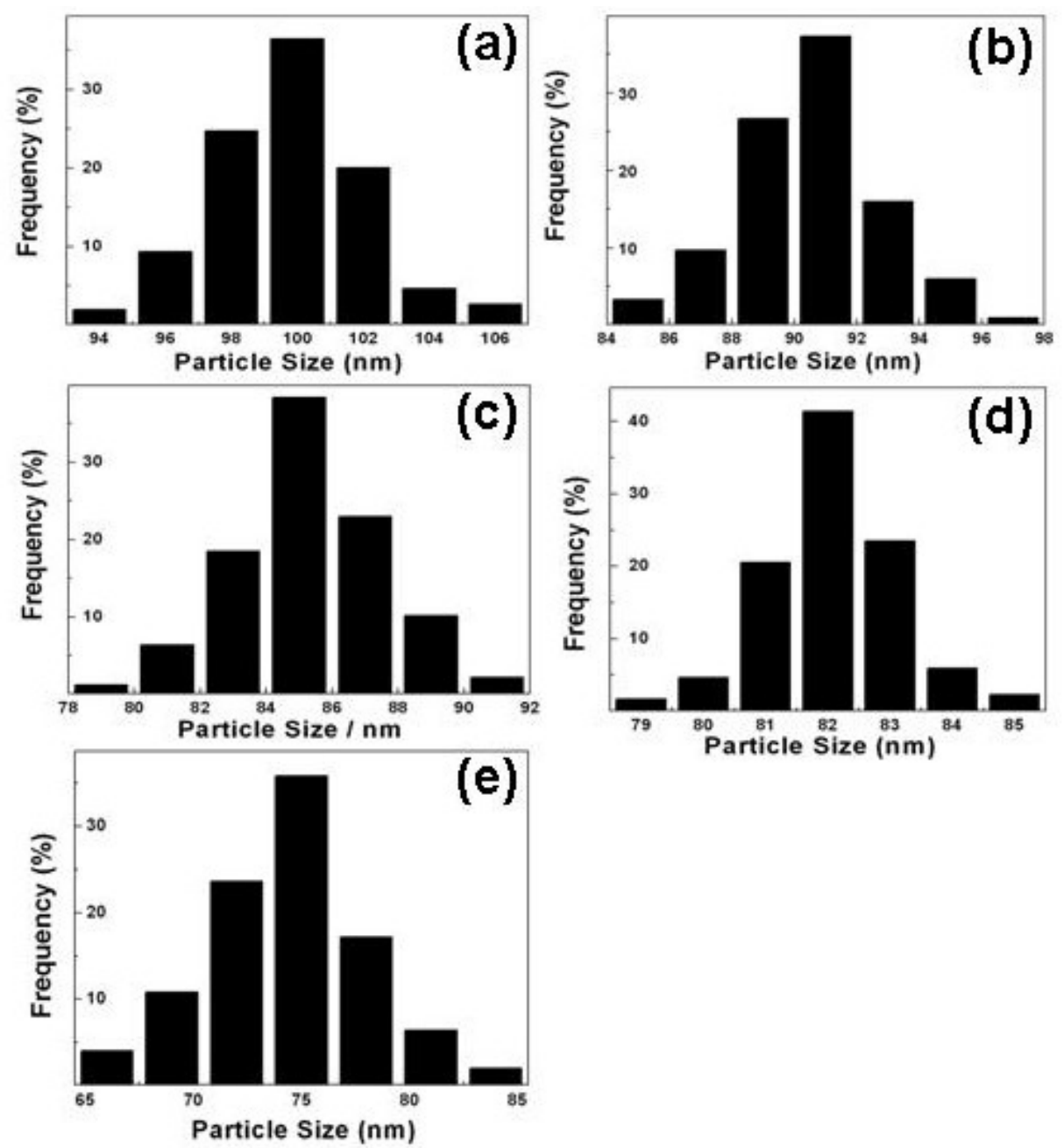

Figure S2. Particle size distributions of the T-series Ni-P nanospheres prepared at different reaction temperatures (a) 333, (b) 343, (c) 353, (d) 363, and (e) $373 \mathrm{~K}$. The corresponding images are shown in Figure 5. 


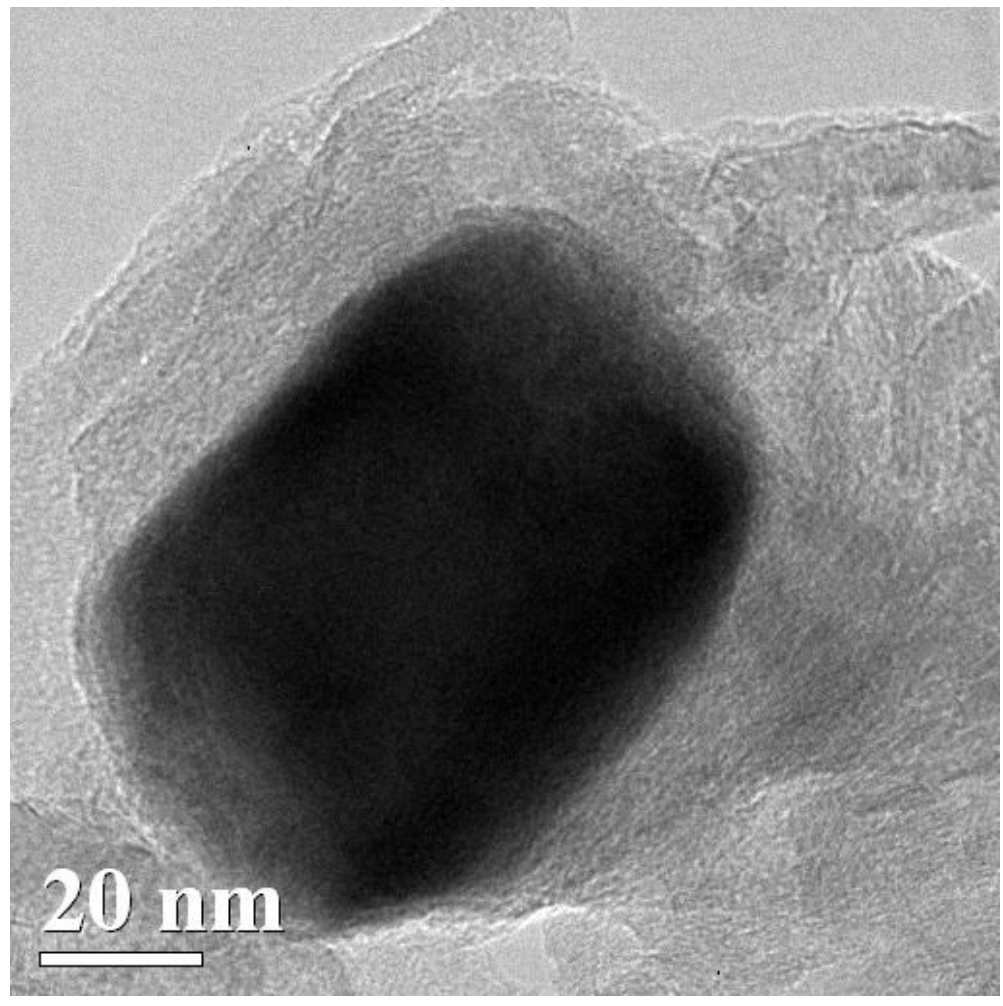

Figure S3. TEM image of a Ni-P particle after catalytic reaction for growing carbon nanofibres. 